\title{
Por Uma Ecologia Dos Direitos Humanos ${ }^{1,2}$
}

\author{
Raffaele De Giorgi*
}

\begin{abstract}
1 Introdução. 2 Os direitos da razão e as razões dos direitos: os catálogos de direitos como esquemas de inclusão. 3 Os catálogos dos Direitos Humanos. 4 A função evolutiva dos Direitos Humanos e o excedente da alteridade. 5 Ambiente externo e ambiente interno da sociedade. 6 Não-lugares de não-pessoas e a hipertrofia dos direitos humanos. 7 A ordem do mundo de uma sociedade heterarquica. 8 Conclusão: ecologia dos Direitos Humanos. Referências.
\end{abstract}

\section{RESUMO}

Este artigo traz a discussão sobre os Direitos Humanos e como são caracterizados por grandes expectativas às quais correspondem sistemáticas desilusões. Nessa perspectiva faz uma reflexão realista sobre a invenção do indivíduo como sujeito unitário, racional e livre, ao mesmo tempo que permite a compreensão da estrutura semântica que tornou possível a elaboração dos Direitos Humanos na sociedade moderna; sua função e contribuição especial para a evolução da sociedade. Pretende ainda refletir sobre o caráter específico da função dos Direitos Humanos, sobre os paradoxos da sua semântica, sobre o seu contributo à produção de alteridade e o excedente dessa produção. Assim, o trabalho propõe mostrar o horizonte de uma possível ecologia dos Direitos Humanos.

Palavras-chave: Direitos Humanos. Sociedade Moderna. Invenção do Sujeito. Alteridade. Ecologia.

1 Tradução do italiano, por: Diego de Paiva Vasconcelos (CV: http://lattes.cnpq.br/5892231067274303); Aparecida Luzia Alzira Zuin (CV: http://lattes.cnpq.br/1584841068017210); Ulisses Schwarz Viana (CV: http://attes. cnpq.br/5011240224774863).

2 Este artigo retoma e amplia a Conferência proferida no II Congresso Internacional de Direito, Cidade e Meio Ambiente na Amazônia: Do Inferno Verde ao Inferno Urbano: Perspectivas para o País, o Estado e a Cidade do Futuro, Porto Velho, Rondônia, 10 agosto 2015.

* Professor titular de Teoria Geral do Direito, Sociologia do Direito e Filosofia do Direito da Faculdade de Jurisprudência da Universidade de Salento, em Lecce, Itália. É também diretor do Centro dos Estudos do Risco, fundado em parceria com o sociólogo alemão Niklas Luhmann. Professor Visitante da Universidade Federal do Rio de Janeiro - UFRJ. Professor Visitante no Max Planck Institut für Europäische Rechtsgeschichte, Frankfurt am Main, Deutschland (2001-2004), Wilhelms Universität Münster, Humboldt Stiftung, Deutschland (2000; 1996; 1991; 1983- 84); Universität des Saarlandes - Institut für Rechts- und Sozialphilosophie, Saarbrücken, Deutschland (1972-1979). Conduz muitos estudos e seminários na América meridional, onde desenvolve estudos e preside a Cátedra de Excelência na Universidade Nacional Autonôma de México (1997-98); desde 2007 até 2011 foi Diretor da Faculdade de Jurisprudência, ano em que foi nomeado diretor de Departamento dos Estudos jurídicos da Universidade de Salento, Itália. É um dos maiores estudiosos italianos na Teoria dos Sistemas Sociais, tendo trabalhado com Niklas Luhmann e publicado em parceria com o seu mestre a Teoria da Sociedade, no ano de 1992. E-mail: <raffaeledegiorgi@gmail.com>. 


\section{INTRODUÇÃO}

A literatura sobre os Direitos Humanos, ainda que seja concluída, apresenta, todavia, características constantes: manifesta expectativas que oscilam entre a esperança e a resignação, entre desilusão do presente e certeza de futuros melhores. Os Direitos Humanos vêm sendo tratados como garantias do reconhecimento da individualidade dos indivíduos, de sua dignidade, de sua liberdade, de sua impossibilidade de repetição da pessoa humana. ${ }^{1}$ Deles se derivam os princípios da propriedade, da igualdade, da proteção contra o Estado, e depois da proteção por parte do Estado. Em seguida pode-se encontrar a violação sistemática desses direitos, e assim se justificam os apelos para que venham respeitados. No nível mais alto das pretensões, protesta-se pela obtenção de sua juridicização. ${ }^{2}$

No entanto, ocorre o que ocorre. Por exemplo, ocorre que os Direitos Humanos puderam coexistir por séculos com a velha escravidão; ${ }^{3}$ ocorre que não obstante as numerosas declarações, essas coexistem com as formas atuais da escravidão: com os mortos do Mediterrâneo, com a guerra cotidiana em cidades como o Rio de Janeiro, com as crianças que morrem exploradas nos navios de pesca do mar da China e com os adultos que aos milhares morrem neste país pelo estresse do trabalho a que são submetidos, ${ }^{4}$ com os campos de detenção dos imigrados, com aquele defeito de cor que nos Estados Unidos leva a polícia a disparar contra os jovens negros que correm pelas ruas; aqui na Amazônia possam coexistir com o Plano emergencial que deveria fortalecer os indígenas para que pudessem resistir ao impacto de Belo Monte. E ocorre que, não obstante seu caráter teológico e messiânico, os Direitos Humanos coexistem com a mais universal violência legítima que tem sempre se abatido sobre o globo terrestre, como aquela que vivíamos desde o início dos anos 90 do século XX, que sempre continua e de modo mais atroz e se justifica com a necessidade de exportar a democracia ocidental.

Queremos refletir sobre os Direitos Humanos a partir de um modo mais realístico, queremos nos indagar qual é a sua função, ${ }^{5}$ queremos ver como operam e queremos tomar a sério o significado dos termos que vêm utilizados quando se fala, exatamente, de Direitos Humanos. Em outros termos, queremos nos indagar: o que está por trás?

\section{OS DIREITOS DA RAZÃO E AS RAZÕES DOS DIREITOS: OS CATÁLO- GOS DE DIREITOS COMO ESQUEMAS DE INCLUSÃO}

Os Direitos Humanos são uma herança do velho Direito Natural. ${ }^{6}$ Eles funcionam de um modo estranho: se ativam quando o Direito se livra de seu vínculo com a natureza, mas, recorrem à natureza para justificar a sua universalidade. São uma herança que se materializa quando as razões do Direito não são mais determinadas pela qualidade das pessoas, que são, precisamente, naturais, mas se fixam na razão. O Direito encontra finalmente as suas razões na universalidade da razão. ${ }^{7}$ Essa grande aquisição se realiza na Europa já no século XVII. Essa 
nova determinação racional do Direito torna-o acessível a todos; todos podem ser titulares de direito à condição de que cada um seja capaz de acessar o direito. Ser capaz a acessar o direito significa ser senhor de si, como dirá Kant. ${ }^{8} \mathrm{O}$ direito é atribuído e reconhecido, é uma demarcação que determina o espaço da ação dentro da qual o agir é lícito. A razão fornece os critérios que permitem, ao mesmo tempo, universalizar e especificar esse direito.

Para que tudo isso seja possível é necessário que aqueles aos quais o direito possa ser atribuído, os titulares do direito, sejam considerados não mais como objeto do direito, mas como sujeitos de direito. Somente sujeitos racionais são capazes de exercitar o direito. Como se vê, aqui estamos diante de um paradoxo - porque também o direito subjetivo é sempre um direito objetivo, como dirá Kelsen, ${ }^{9}$ isto é, um direito que constrói como seu objeto o sujeito que é autorizado a exercitá-lo -, mas o paradoxo é muito frutífero. Para que esta operação da construção do sujeito possa funcionar, por sua vez, será necessário que os sujeitos de direito sejam considerados como indivíduos, como individualidades, como diferenças, como particularidades. Ou seja, devem ser tratados pelo Direito na sua integralidade, na sua totalidade. Somente assim as ações poderão ser imputadas aos singulares, isto é, aos indivíduos, a complexos unitários que não podem ser divididos. ${ }^{10}$ Estes complexos unitários, chamados de indivíduos, precisamente, podem coordenar as ações e estabelecer relações entre fins e meios, isto é, podem ser sujeitos de um agir racional. Naturalmente o sujeito da imputação deverá ser pressuposto como livre, diversamente a ação não lhe poderia ser imputada.

Essa invenção do indivíduo como sujeito unitário, racional e livre terá particular relevância na futura construção dos catálogos de Direitos Humanos. O complexo das atribuições e dos requisitos que são necessários para a representação unitária do destinatário da imputação será recolhido ao interior de uma concha protetora: esse invólucro poderá ser facilmente utilizado como referência da comunicação; isso se chama pessoa. ${ }^{11}$ A pessoa é uma exterioridade da comunicação que oculta a diferença das particularidades. A pessoa é, precisamente, uma máscara, de acordo com a correta etimologia latina.

O velho Direito Natural não podia funcionar mais como um vínculo normativo à construção das expectativas dirigidas ao futuro, porque se consumava a força legitimante da ideia de natureza sobre a qual ele próprio podia ser construído. Agora se dirá que a natureza do indivíduo é aquela de ser um sujeito racional. A obra de Cartésio havia desenhado o perfil dessa individualidade do sujeito. Para que o mundo não seja despedaçado pela ameaça do mal que podia ser causado pelas ações dos indivíduos, é necessário que a razão se conserve e a autoconservação da razão se realize por meio do agir racional ${ }^{12}$ do indivíduo. Por isso, os indivíduos racionais encontram um acordo recíproco na base do qual se fixam os espaços do recíproco reconhecimento do agir de cada um. $\mathrm{O}$ racionalismo havia elaborado o esquema do contrato social: de acordo com esse esquema os indivíduos deveriam ser pensados como capazes de se vincular e de respeitar as condições do pacto. Essas condições legitimavam o poder e impunham tratar os particulares como indivíduos. Em outros termos, estava consu- 
mada a estrutura da velha estratificação social e no horizonte se perfilava uma sociedade que não tolerava mais a centralidade e a verticalidade, assim como não tolerava mais a ordem das castas e a ordem das corporações.

Essa forma da sociedade se chama sociedade moderna: ${ }^{13}$ a qual era exposta às ameaças particulares, era exposta às resistências, aos riscos de involução que provinham da velha ordem; para resistir a essas pressões deveria ser estabilizada. A estabilização deveria poder manter a nova norma das ações e, assim, para evitar as ameaças do passado, deveria abrir-se ao risco do futuro.

\section{OS CATÁlOGOS DOS DIREITOS HUMANOS}

Os catálogos dos Direitos Humanos fornecem esquemas de referência úteis para a estabilização das possibilidades do agir nessa sociedade moderna, quais sejam: do agir político, do agir jurídico, do agir econômico; esses são esquemas da inclusão de todos no universo das possibilidades do agir. Essa inclusão universal, de fato, é o correlato da universalidade da razão. Deve estar claro, contudo, que a inclusão de todos se torna possível porque a seleção dos espaços reais do agir é confiada a cada sistema social. A autoconservação da razão, na realidade, significa que isso que se conserva são as razões de cada sistema social. A função da universalidade da razão torna possível o acesso, mas a seletividade das possibilidades do agir é a seletividade evolutivamente alcançada por cada um dos sistemas sociais.

Os Direitos Humanos têm a função de manter abertas as possibilidades de inclusão: deixam abertos os espaços entre os quais se realizarão as modalidades reais de inclusão, as quais, repetimos, são confiadas a cada um dos sistemas sociais da sociedade moderna. Por isso se diz que os Direitos Humanos são garantias, porque nada podem em relação à gestão real da inclusão e de suas consequências. Fixam as condições de generalização, ou seja, da indiferença em relação ao caso específico: a dignidade é intocável, de acordo com o primeiro artigo da Constituição alemã. Mas a medida de um tratamento penitenciário "digno" é fixada pelo Direito Penal. Se um réu é construído como altamente perigoso, pode ser mantido em uma cela de isolamento de dois metros quadrados, com a luz acesa por vinte e quatro horas e privado da possibilidade de falar. Ou então pode ser esquecido em Guantánamo. A dignidade não é tocada. E não é o caso de recordar qual seja a cor da pele da dignidade, ou quais sejam as suas orientações sexuais. A dignidade é vulnerabilíssima, por isso é "intocável”. E quando os sistemas sociais parciais "tocam-na”, há sempre um fator da seleção que abaixa ou levanta o nível da "intocabilidade".

Dignidade, ${ }^{14}$ então, é aquele reconhecimento que é atribuído a cada um que seja e que lhe permite acessar a comunicação social sem que a sua participação prejudique ou interrompa a continuidade da própria comunicação. Dignidade, então, é um esquema da autorrepresentação que permite aos indivíduos se sentirem pessoas, isto é, indiferenças que 
podem afirmar sua diferença, que, por sua vez, lhes permite não serem confundidos com outras indiferenças; todavia, a tolerabilidade da diferença é objeto de seleção por parte da estrutura de qualquer sistema social. Em um clima que preanunciava o Nazismo na Alemanha dos anos trinta, do século XX, quem praticava o homossexualismo era condenado com base na aplicação de uma velha lei sobre a tutela da raça e do sangue germânico. Não é diferente do que ocorre com a "igualdade". ${ }^{15}$

Os Direitos Humanos são considerados como um direito superior. Na realidade ocupam o espaço intermediário que separa, mas se pode também dizer acopla, o Direito e a Política.

Aos Direitos Humanos se atribui uma posição privilegiada por meio da sua fundação sobre um valor. Os valores, na verdade, são apresentados como absolutos, ou seja, como exclusivos. Na realidade, porém, aquilo que torna absolutos os valores é o fato de que, na sua paradoxal fundação, se exclui a outra parte, aquela parte que é simplesmente negada e que faz aparecer o valor como único. Igualdade, por exemplo, é apenas uma parte de uma distinção da qual a desigualdade é a outra parte. Uma não pode existir sem a outra. Se observa-se isso que vem ocultado por meio do paradoxo da igualdade, vê-se que igualdade e desigualdade crescem simultaneamente. Também os sistemas sociais operam do mesmo modo: cada sistema reconstrói o mundo a partir de sua perspectiva e, por consequência, na sociedade moderna cresce ao mesmo tempo, seja a inclusão, seja a exclusão.

\section{A FUNÇÃO EVOLUTIVA DOS DIREITOS HUMANOS E O EXCEDENTE DA ALTERIDADE}

Se a função real dos Direitos Humanos consiste na realização das condições que estabilizam a forma da modernidade da sociedade moderna, então não se pode, por certo, negar que tenham uma função evolutiva: bloqueiam a involução, impedem que o passado inunde o presente com seus detritos. Sabemos, de fato, que evolução social sempre produz destruição. Esta acumula escombros: é assim que o passado aparece na evolução, como lugar no qual se acumulam escombros, detritos. Os Direitos Humanos, assim, realizam espaços de possibilidade para que a evolução não destrua a si mesma, mas aja de modo a reproduzir condições evolutivas. A garantia de subsistência dessas condições evolutivas depende do fato de que na sociedade se rompa a cadeia de determinações: também essa ruptura, naturalmente, é o resultado que se produz na evolução. Às determinações se substituem possibilidades. ${ }^{16} \mathrm{~A}$ modernidade não é outra coisa senão o resultado dessa transformação, cuja transformação se torna condição da abertura de um particular horizonte: trata-se do horizonte no qual a improbabilidade se transforma em possibilidade. Quando aquele horizonte se delineia, a evolução abre o caminho para si mesma. É claro que a transformação da improbabilidade em possibilidade evolutiva se realiza por si. Entretanto, na sociedade devem existir dispositivos que realizam as condições de possibilidade dessa transformação. 
Ora, o esquema dos Direitos Humanos contribui à produção de condições cujas improbabilidades evolutivas se transformam em possibilidade. $O$ mecanismo pode ser descrito deste modo: o agir dos indivíduos, assim como o agir dos sistemas sociais, é continuamente exposto à contingência, ou seja, é aberto sempre às possibilidades sempre diversas, as quais todas devem estar acessíveis: podem ser condicionados, mas não podem ser determinados. Porém, também o condicionamento ao qual estão submetidos aumenta a necessidade de procurar alternativas, isto é, aumenta a contingência. Porque cada tratamento da contingência produz outra contingência. E contingência significa possibilidade daquilo que é outro. É aqui que o esquema dos Direitos Humanos funciona como técnica de abertura ao futuro e, assim, como técnica da transformação de improbabilidades em possibilidades evolutivas.

O que significa tudo isso? Significa que o esquema dos Direitos Humanos contribui para a estabilidade da sociedade moderna porque deixa aberto o espaço para a contínua produção do outro, para a contínua emergência daquilo que é outro. O esquema dos Direitos Humanos garante o funcionamento da estrutura típica dessa sociedade, a qual assegura a si mesma a contínua produção de um excedente de alteridade. Nosso tema, então, é esse excedente de alteridade.

Quando nos anos 1600 foi delineado o perfil da razão, emergiu a possibilidade de todos acessarem-na. Essa possibilidade permitia combater o privilégio. Todos podiam servir-se da razão para orientar suas ações e usar o agir racional orientado ao fim como técnica de inclusão, como requisito para obter o reconhecimento. Mas, ao mesmo tempo emerge a outra parte da razão, la déraison: para proteger o perfil da razão, era necessário indicar os modos de ser da déraison. E foi assim que se tornou manifesta a ameaça da déraison e a multiplicidade de suas manifestações. Foi assim também que se viu quão grande era o espaço da ação que podia ser ocupado pela déraison. Um excedente de alteridade. Explica-se desse modo o fato de que a invenção da razão moderna teve como sua real consequência a grande internação da qual fala esplendidamente Foucault. ${ }^{17} \mathrm{~A}$ internação em massa se justifica com a necessidade de proteger a razão. No entanto, no universo da inclusão, aquilo que deve ser protegido é a razão do Direito, a razão da Economia, a razão da Política. São essas as razões da razão.

É claro que a indicação de uma parte exclui a outra parte. A déraison como a outra parte da razão, deve ser mantida à parte, deve ser excluída, deve ser ocultada. A razão tem sua razão de ser na sua unicidade, ou seja, na sua identidade consigo mesma. Identidade, dizia Luhmann, é manter o outro à distância. Aquilo que é outro de si mesmo é tratado como aquilo que é outro, nesse sentido, deve ser mantido à distância. A razão, que é o si mesmo, não tolera a simultânea presença do outro. Uma vez inventada a razão, a outra parte se torna um problema, ao qual se responde com a grande internação. Uma situação que ninguém transformou em grande motivo literário como Machado de Assis, na obra O Alienista.

A velha metafísica e a velha ontologia tratavam a alteridade como não-ser, como negatividade. A sociedade moderna, em vez disso, constrói a alteridade como correlato das operações 
seletivas de cada um dos sistemas sociais. Como aquilo que deve ser mantido à distância. Porque somente ao manter-se à distância se torna visível a identidade. Mas torna possível também o tratamento da alteridade. Qualquer tratamento será sempre justificado, assim como será sempre justificada a expectativa do outro de ser objeto de tratamento.

Quando Ginés de Sepúlveda sustentava que os índios eram bestas feras utilizava argumentos da velha metafísica. A Bula Veritas ipsa de Paulo III, de 1537, em vez disso, utilizou argumentos mais modernos: a Bula define os índios como homines veri; com essa definição, porém, pretende negar que os índios fossem fera bestia porque assim se podia motivar a sua capacidade de ser cristianizados, no que se refere à sua liberdade. Desse modo a Bula pretende dar a entender que não se deve ter os índios como escravos e que não lhes deveriam ser subtraídas suas coisas. Mas, o mais interessante, o fato de que a Bula não se ocupou da questão da racionalidade dos índios, em nenhum momento essa questão é de fato tratada. Não se colocou essa questão como problema. O Papa se preocupou sobre o tratamento dos índios somente para fins de inclusão no sistema da religião, contudo não exatamente de sua inclusão no sistema da sociedade. Não é o caso de maravilhar-se se na metade dos anos cinquenta do século passado a Suprema Corte dos Estados Unidos tenha trabalhado na interpretação da doutrina separate but equal.

Retornemos aos índios: assim construídos, são excedentes da comunicação social. São natureza, são ambiente externo da sociedade. Contudo, quando eles reagiram à espoliação das terras, quando ocupam as terras que sempre foram deles, quando se opuseram à redução à escravidão, então tiveram que ser reconhecidos: reconhecidos como outro. Eles não serão mais natureza, mas, por meio do reconhecimento, tornaram-se alteridade construída pela razão ocidental: a razão do Direito, a razão da Economia; a razão da Política. Somente então, tiveram uma cultura, puderam ser tratados enquanto tal, puderam ser objeto de tutela, de garantias, ou confiados à filantropia. Por tudo isso, demorou pelo menos dois séculos para que os índios como natureza fossem dizimados, como árvores que são abatidas por motivos comerciais, como terras desflorestadas.

Como alteridade construída, tornam-se ambiente interno da sociedade, como a déraison: eles podem ser não-proprietários, não-aculturados, não-cidadãos, não-sãos, não-civilizados. São, em outros termos, alteridade que excede e que torna possível a identidade de qualquer coisa, da qual são a outra parte. O esquema dos Direitos Humanos dispõe de malhas suficientemente largas para que através delas possam passar diferentes alternativas. Naturalmente, deve estar claro que os índios não são apenas inventados como índios, mas continuamente reproduzidos como índios. Ocorre que agora são índios brasileiros ou índios mexicanos, índios que votam e, provavelmente, índios que vão à escola. São alteridades diferentes, mas são sempre excedentes que podem ser tratados.

A Terra também é, naturalmente, a fonte da produção de excedente de alteridade. Vejamos: até quando a Amazônia era natureza, era floresta, constituía-se somente de uma 
fonte de produção de oxigênio para todo o globo terrestre. Mas, quando a Amazônia passa a ser tratada como espaço civilizado pela Política, pelo Direito e pela Economia, então a Terra se torna propriedade, adquire valor, converte-se em espaço do agir racional: e a razão do Direito exclui os não-proprietários, inclui os ocupantes, as populações são tratadas de modo diferenciado, os elementos que integram as comunidades são tratados como indivíduos, complexos unitários tornam-se personalidade jurídica. Nessa perspectiva, também a razão da Economia deve utilizar a diferença entre aquilo que tem valor e o que não tem valor, ou então, entre ter dinheiro e não-ter dinheiro. É assim que os habitantes, do mesmo modo inventados como sujeitos racionais, tornam-se excedente. Tornam-se qualquer coisa diferente da natureza. Tornam-se uma construção jurídica. E de tal construção se poderá discutir se, para o propósito de sua inclusão, deverá ser tratada de um modo ou de outro.

Assim a Terra, mais que frutos, produzirá excedente de alteridade. A Terra poderá ser ocupada, transmitida por herança, tornada produtiva ou transformada em reserva, ou então utilizada para a construção de grandes obras ou de grandes cidades. Tudo isso será um excedente que poderá ser tratado de qualquer modo. Nesses termos, a Amazônia pode ser desflorestada, uma Amazônia atravessada por centrais hidroelétricas, uma Amazônia de povos em fuga, uma Amazônia que vive, uma Amazônia que morre. De uma parte a natureza humana, animal, vegetal ou mineral, da outra uma natureza que se torna ambiente da sociedade.

\section{AMBIENTE EXTERNO E AMBIENTE INTERNO DA SOCIEDADE}

Sobre o ambiente da sociedade merece mencionar sobre "urbanizar". Urbanizar significa transformar o ambiente externo da sociedade em ambiente interno da sociedade. Significa transformar aquele que é dado como natureza, naquilo que é construído como artificial.

A primeira distinção que se constrói simultaneamente com a construção da cidade é a distinção entre centro e periferia. Todavia, essa distinção não diferencia somente lugares, ela diferencia a sociedade, diferencia funções sociais: ela transforma espaços urbanos em periferias da sociedade. Aqueles que construíram a cidade, e para tal construção se utilizaram das mãos, se diferenciam daqueles que para construir a mesma cidade se utilizam das finanças. Essa diferença centraliza alguns e faz periferia dos outros. Com respeito ao centro, a periferia é um excedente, periferia é alteridade, deve ficar de fora, mas pode ser objeto de tratamento, ou seja, de inclusão condicionada. Ela pode ser tratada como periferia com base na cor, como destinatária da alocação dos excedentes da cidade, do ponto de vista alimentar, higiênico, sanitário, escolar e político. Mas, por meio de um processo de externalização que é determinado pela estrutura das periferias da sociedade, a periferia urbana se torna facilmente espaço de alocação dos resíduos do passado, torna-se teatro de uma espécie de "economia moral"18, espaço de alocação do crime, da violência. Nas periferias, de fato, há sempre integração entre os indivíduos. Essa integração depende do fato de que nas periferias criam-se condições de estreita dependência entre os indivíduos: 
cada um depende de algum outro que depende sempre de algum outro. As prestações sociais podem ser satisfeitas somente por meio de ajuda recíproca. Por meio de apoio dos membros da família, da vizinhança, daqueles que têm mais meios à disposição e os utilizam para construir cadeias de dependência. É claro que o apoio daqueles que têm mais força e podem utilizá-la para construir hierarquias da dependência torna-se fator daquela forma estreitíssima da interação que se manifesta como criminalidade organizada. Como se pode ver facilmente, esse excedente de alteridade se produz no espaço de ação dos Direitos Humanos. Ninguém poderá afirmar que viver na periferia é uma violação da dignidade, ou que a um índio expulso de sua terra seja impedido o exercício de um direito. A escravidão foi juridicamente abolida no fim do século XIX, nesses termos os trabalhadores são livres, como dizia o socialismo daquele mesmo século, para vender a alguém sua força de trabalho. Mas, como as favelas do Rio de Janeiro, no Brasil, se explicam com a abolição da escravidão, do mesmo modo aquelas que circundam Brasília se explicam com a construção da cidade: aqueles que construíam, depois do trabalho se tornavam materialmente inutilizáveis, excesso para deixar de fora, tornavam-se ambiente da cidade, precisamente.

Do mesmo modo a violenta espoliação das terras das comunidades indígenas na Amazônia justifica-se com o desenvolvimento que deve ser assegurado pela energia produzida pelos monstros das centrais hidrelétricas. Por exemplo, na realização do monstro de Belo Monte, Altamira - PA, com a organização de um conhecido Plano Emergencial, cuja execução, na ausência de organismos públicos, é confiada à empresa privada Norte Energia. "O Plano Emergencial tinha como objetivo criar programas específicos para cada etnia, para que os indígenas estivessem fortalecidos na relação com Belo Monte. A ideia é que os índios se empoderassem, para não ficar vulneráveis diante do empreendimento." ${ }^{19}$

Em uma esplêndida entrevista concedida em 2014 ao diário El País, ${ }^{20}$ o membro do Ministério Público Federal, Thaís Santi, assim descreve o espetáculo que pode pessoalmente assistir:

A filantropia, os biscoitos recheados, os refrigerantes, a coca cola, o chocolatinho para as crianças. "Era como se fosse um pós-guerra, um holocausto. Os índios não se mexiam. Ficavam parados, esperando, querendo bolacha, pedindo comida, pedindo para construir as casas. Não existia mais medicina tradicional. Eles ficavam pedindo. E eles não conversavam mais entre si, não se reuniam. $O$ único momento em que eles se reuniam era à noite para assistir à novela numa TV de plasma. Então foi brutal. E o lixo na aldeia, a quantidade de lixo era impressionante. Era cabeça de boneca, carrinho de brinquedo jogado, pacote de bolacha, garrafa pet de refrigerante.

Os índios em fila diante dos escritórios da Norte Energia, sem saber o que perguntar, porque para eles já lhe havia sido retirado tudo que tinham e queriam ter somente aquilo que sempre haviam tido. Thais narra:

Esse grupo de recente contato estava comendo bolachas e tomando refrigerantes, estava com problemas de diabetes e hipertensão. Mas o meu impacto mais 
brutal foi quando eu estava tentando fazer uma reunião com os Arara, e uma senhora, talvez das mais antigas, me trouxe uma batata-doce para eu comer.

É dessa maneira que os habitantes das terras são transferidos; seus usos e costumes são acuradamente salvaguardados; pelo respeitoso tratamento das comunidades são elaborados grandes projetos, as grandes empresas de construção se comprometem por contrato com o Governo Federal a ocupar-se das exigências dos novos marginalizados exatamente para evitar que sejam marginalizados.

\section{NÃO-LUGARES DE NÃO-PESSOAS E A HIPERTROFIA DOS DIREITOS HUMANOS}

A estrutura da diferenciação da sociedade moderna considera racional utilizar pequenas diferenças para produzir as grandes diferenças e externalizá-las. Desse modo reúne no seu interior formas de uma estabilização evolutivamente útil. As grandes metrópoles do mundo ${ }^{21}$ deixaram crescer em seu interior os conhecidos slums que já reúnem milhões de pessoas. Cidades como Jacarta, como Mumbai, como Cidade do México são ocupadas por monstruoso excedente de alteridade. Na Etiópia, $75 \%$ da população vive em slums. Na mesma direção, quatro milhões de sírios estão em fuga; quando param estão acampados em pequenos cantos de uma terra que queima. Milhões de corpos, milhões de não-pessoas, grande parte das quais não tem existência social, porque não tem existência jurídica; não tem endereço, não são cidadãos, como se diz com eufemismo que já perdeu sua nobreza. Estas não-pessoas são mantidas diante da porta da lei, como no maravilhoso conto de Kafka, mas em um sentido diverso de tantos sentidos que frequentemente são atribuídos à metáfora kafkiana do camponês: aqui a porta da lei diante da qual envelhecem as não-pessoas não tem nenhum caráter messiânico. Aqui a lei é o sistema do Direito moderno o qual, obviamente, não vê que não vê aquilo que não vê. Um corpo não é um indivíduo, assim como um não-indivíduo não é uma pessoa. Sem qualificação jurídica, isso é, sem a atribuição de um reconhecimento jurídico, a pessoa, isso é, o invólucro das atribuições é privado de conteúdo. E um invólucro privado de conteúdo não existe. O slum, então, é um não-lugar de não-pessoas. Assim como diante de uma central hidroelétrica um índio é uma não-comunidade e uma não-comunidade ocupa um não-território.

Pode compreender-se agora porque ao camponês de Kafka ${ }^{22}$ que está para morrer e, depois de haver esperado a vida inteira para entrar na lei, não pode mais esperar, o guardião da lei pode dizer: esta porta estava aberta somente para ti. Agora vou e fecho-a. A alteridade deve restar na antessala da lei - para usar uma interessante expressão de L. Nuzzo: a alteridade pode sempre entrar, mas desse modo se produzirá outra alteridade.

Os Direitos Humanos, em outras palavras, regulam a abertura e o fechamento ao mesmo tempo. Por isso, têm características paradoxais. Diz-se que, quando são colocados 
na forma do valor, adquirem fundamentos estáveis. Uma afirmação privada de sentido. Se isso tivesse sentido, como se poderia fazer uma comparação de "valores"? O que significa "ponderação" 23 de valores? Quem é o observador que pode decidir se o valor propriedade tem mais valor que o valor dignidade? Em relação a este, o valor do valor da vida? Vejamos: no ano 2014, na zona norte do Rio de Janeiro, mil e setecentos policiais liberaram um terreno que era de propriedade da $\mathrm{O} i$; o terreno já estava abandonado há muitos anos, eram espaços livres e galpões decadentes, e estava ocupado por cinco mil pessoas, muitas das quais eram "moradores de rua"; muitas outras, ao contrário, viviam nas ruas por efeito do incremento dos custos dos aluguéis nas favelas, que se verificava em toda a cidade em consequência da Copa do Mundo.

Como pode o observador avaliar o valor do valor propriedade como mais alto ou como primário em face do valor do valor vida ou dignidade ou igualdade? Os Direitos Humanos são sempre respeitados. $\mathrm{O}$ observador posto no interior da sociedade vê aquilo que vê, ameaça à forma da diferenciação social; assim, o ambiente externo da sociedade que ameaça suprimir a diferenciação. O observador vê o que vê. Se se viola o direito de propriedade, se danifica a economia, o mercado, a livre circulação de bens, rompe-se a diferença entre público e privado. E poderíamos continuar, naturalmente. Mas nada de tudo isso pode ser tolerado, dado que o espaço dos Direitos Humanos é suficientemente flexível: uma vez restabelecidas as condições da diferenciação, aquele espaço pode ser reaberto, alargado, estendido em outro modo, por exemplo, por meio da intervenção do sistema político.

Aquilo que caracteriza o Direito moderno é o alto nível da artificialidade da qualificação jurídica. O grande jurista alemão F. Carl von Savigny podia dizer que o sistema do Direito é resultado da Lógica e da Filosofia. ${ }^{24}$ Aquilo que antes vinha elaborado por meio de uma filosofia da natureza, ou ainda, por meio das determinações dos gêneros e das espécies, agora vem determinado da natureza da coisa. Mas a coisa é agora somente uma coisa jurídica, um construto lógico conceitual por meio do qual o Direito deriva outros construtos lógico-conceituais. O índio, o slum, a favela, o homossexual, o negro, o náufrago, o requerente de asilo tornam-se um problema quando são inventados como construtos lógico-conceituais. Enquanto estão na antessala da lei, o Direito não os vê. Quando eles cruzam a soleira da porta da lei o Direito os constrói como sua realidade. Como realidade do Direito, não como realidade no sentido comum do termo.

A forma dos Direitos Humanos, então, pode ser definida como um esquema que permite ao Direito expor-se à contínua evolução, isto acontece porque a moldura dos Direitos Humanos deixa aberta ao Direito a possibilidade de alcançar níveis sempre mais altos de artificialidade, níveis sempre mais refinados de sedimentação jurídica da comunicação social: aquela moldura deixa ao Direito a possibilidade de elaborar tecnologias conceituais sempre mais complexas. Isso ocorre também porque aquela moldura reabre continuamente o espaço social destinado ao sistema político. 
A evolução do Direito, assim como a estabilização evolutiva da forma da diferenciação social, também constitui as características mais relevantes da modernidade, que são limitadas a uma parte dos países que ocupam o globo terrestre e são realizadas em modalidades diferentes. A forma do catálogo dos Direitos Humanos se coloca no espaço intermediário entre o sistema jurídico e o sistema político. Aqueles direitos estão expostos seja à Política, seja ao Direito, o que significa que são caracterizados por uma alta sensibilidade nos confrontos de ambos. Ora, se a modernidade produz continuamente excedentes de alteridade, e se o Direito usa esses excedentes para produzir Direito, então a produção de alteridade é imparável.

A gestão da alteridade sempre foi uma gestão confiada ao sistema político, o qual, na sua história agiu de modos diferentes, adotou políticas de inclusão, ameaçou o Direito, moralizou a Economia, como acontecem com aquelas políticas que se chamam neoliberais: fazem guerras e depois firmam os tratados de paz para continuarem em paz com as suas guerras. O século passado viu grandes tragédias nas quais, sem tanta vergonha da história, consumaram-se as decisões políticas sobre a gestão dos excedentes de alteridade.

E com aquelas decisões se consumaram também as ilusões sob a forma do poder moderno e de seu Direito. Porém, aqueles excedentes não eram excedentes produzidos pelo normal funcionamento da diferenciação da sociedade. Na última parte da segunda metade daquele século, realizaram-se condições que no presente tornaram impossíveis a gestão política do excedente de alteridade. E, assim, abre-se o espaço para uma hipertrofia dos Direitos Humanos: fala-se muito, fala-se continuamente, cada pretensão é formulada com o recurso a eles; assim, pretende-se que o Estado lhes afirme contra o Estado e contra as corporações, pretende-se que a comunidade internacional lhes afirme contra a indiferença da comunidade internacional.

\section{A ORDEM DO MUNDO DE UMA SOCIEDADE HETERARQUICA}

O sistema da sociedade moderna é o sistema de uma única sociedade. Digamos que essa sociedade é sociedade do mundo porque o mundo, como seu limite, é sempre presente na comunicação social. Todavia, no seu interior nem todos os sistemas sociais são universalizados do mesmo modo. E sistemas sociais plenamente universalizados como aquele da Economia ou do conhecimento não podem ser controlados por outros sistemas sociais que não alcançaram o mesmo nível de universalização. E, assim, a modernidade dessa sociedade se funda propriamente sobre a heterarquia, ${ }^{25}$ ou seja, na impossibilidade de qualquer hierarquia que seja. E então, ao fim do século XX, a política que tem no Ocidente o seu centro de elaboração das representações dos problemas universais transformou aquela sua centralidade em uma pretensão de colocar ordem no mundo. $\mathrm{O}$ mundo resistiu à imposição da ordem e implodiu em si mesmo deixando emergir a selvagem ordem das coisas que o tempo havia escondido. 
E, de fato, o mundo conhecia tantos lugares do mundo que se consideravam centros e que tentaram impor ordem ao mundo; desde as antigas cosmologias, aos romanos, aos cristãos, aos árabes e até aos modernos fascismos. As tentativas recentes de construir a ordem do mundo eram justificadas pela ameaça da desordem do mundo. Dizia-se que era necessário exportar a democracia, e assim foram organizadas "as grandes tempestades no deserto", aquelas tentativas todas fracassaram miseravelmente. Aqueles fracassos deixaram atrás de si grandes abismos: fendas da Política e do Direito, lugares preferidos da cega voracidade das finanças. O mundo agora ameaça a si mesmo e não encontra proteção contra si mesmo.

A essas condições do mundo, a produção de excedente de alteridade está difundida de modo inobstável e irreprimível. Uma guerra universal molecular se difunde entre as alteridades produzidas por detritos da ordem que se queria impor; essa guerra do mundo contra o mundo apropriou-se das cidades e das planícies, dos desertos e das montanhas, das ruas, das vilas, das ravinas e dos bairros esquecidos. Velhas unidades que tinham a forma de Estados, de Estados patrimoniais, de características tribal, étnica, religiosa, patriarcal, e que são despedaçadas e disseminaram por seu entorno detritos humanos: são as não-pessoas que são sobreviventes e que correm pelo mundo: Vidas Secas. ${ }^{26}$ Eles correm em direção ao Ocidente, em direção à Europa, mas também em direção à América Latina, correm por mares e terras. Correm em direção às terras habitadas por pessoas, daqueles que são incluídos, porque o Direito os trata como seus objetos e vivem enclausurados dentro de barricadas que eles ergueram para proteger-se da invasão dos excluídos. Corpos que se iludem de poder tornarem-se pessoas; fugitivos de guerras e fugitivos da paz; vítimas das suas cores ou de sua religião, presas da rejeição étnica o do prejuízo político, reféns de grupos que por sua vez são grupos de reféns. Um universo de corpos que o Direito mantém longe da sua porta, permitindo o aproximar-se de sua soleira como mercadorias que serão utilizados na medida e nas circunstâncias oportunas.

Há, entretanto, outra ordem do mundo que à vez disso domina sem qualquer oposição: a ordem das finanças. A ordem de uma economia universal que é reduzida à escravidão por sua própria organização, pelas finanças. $\mathrm{O}$ universo das finanças é o universo do valor que não tem valor, mas, que permite transformar tudo em valor. As artificialidades do Direito não podem seguir a convulsiva rapidez das transformações do valor, e a Política pode intervir agora somente com a atitude do post-decisional-regret: recusa das decisões depois que essas foram tomadas. A Política corre atrás das consequências de suas decisões. A primeira consequência do monopólio social das finanças é constituída pelo fato que à estável produção de excedentes de alteridade, agora se soma também à contínua ameaça de expulsão daqueles que eram incluídos. Basta considerar aquilo que aconteceu em nível planetário nos últimos anos e a ameaça que se torna iminente a cada dia em nível planetário. Nessas condições, cerca de um bilhão de pessoas vive atualmente nas favelas e o número arrisca estender-se até o dobro nos próximos anos. O futuro tem o horizonte do dia seguinte, e perguntamos: e os Direitos Humanos? 


\section{CONCLUSÃO: ECOLOGIA DOS DIREITOS HUMANOS}

Os catálogos dos Direitos Humanos, assim como as numerosas declarações que abrem contínuos espaços de expectativas, são construtos de observadores que observam a partir do interior da sociedade. São observadores que usam a distinção entre sistema e ambiente. Eles alimentam expectativas que são dirigidas aos catálogos dos Direitos Humanos porque, a partir do interior da sociedade, não se vê aquilo que está no exterior dela. $\mathrm{O}$ ambiente não se vê. $\mathrm{O}$ ambiente é ameaça porque é mais complexo que o sistema. E os observadores veem somente as ameaças. Ocorre que esse ambiente é o ambiente do sistema. O sistema não poderia existir sem o ambiente, o qual não é um dado natural, é ele próprio uma construção do sistema. O ambiente é a "descarga" de acordo com o qual a sociedade tem o excedente de alteridade que essa mesma produz.

Uma ecologia dos Direitos Humanos, ou seja, uma observação dos Direitos Humanos que pressupõe a perspectiva da relação do sistema da sociedade com o ambiente deste sistema, uma perspectiva que observe como sua construção as relações que a sociedade constrói com o seu ambiente; em outras palavras: uma perspectiva que observe como no ambiente da sociedade, a sociedade aloca as alteridades que produz, tal perspectiva poderia permitir-nos ver, realistamente, e perguntar-nos: qual é a função dos direitos humanos. E quais são as possibilidades de futuro que se podem construir a partir dessas observações.

\section{REFERÊNCIAS}

ALEXY, Robert. Theorie der juristischen argumentation: die Theorie des rationalen Diskurses als Theorie der juristischen Begründung. Frankfurt: Suhrkamp Verlag, 1983.

. Theorie der grundrechte. Frankfurt: Suhrkamp Verlag, 1987.

DE GIORGI, Raffaele. Ciência do direito e legitimação: crítica da epistemologia jurídica alemã de Kelsen a Luhmann. Curitiba: Juruá, 2017.

. Azione e imputazione: semantica e critica di un principio nel diritto penale. Lecce: Milella, 1984.

. Modelos jurídicos de la igualdad y de la equidad. In: . Los derechos fundamentales en la sociedad moderna. México: Editorial Fontamara, 2015.

GÖTZ, Norbert. Moral economy: its conceptual history and analitical prospects. Journal of Global Ethics, United States, v. 11, p. 147-162, 2015.

GRIMM, Dieter. Die Zukunft der Verfassung. Frankfurt: Suhrkamp Verlag, 1991.

FOUCAULT, Michel. Surveiller et punir: naissance de la prison. Paris: Gallimard, 1993.

KAFKA, Franz. Vor dem Gesetz (1915). In: . Der Proceß. Frankfurt: Insel Verlag, 1990. v. 3. p. 226. 
KANT, Immanuel. Die Methaphysik der Sitten. Frankfurt: Suhrkamp Verlag, 1982. v. 8. KELSEN, Hans. Reine Rechtslehre: einleitung in die rechtswissenschaftliche Problematik. Leipzig: Franz Deuticke Verlag, 1934.

LUHMANN, Niklas. Grundrechte als Institution. Berlin: Dunker \& Humblot, 1965.

. Das Recht der Gesellschaft. Frankfurt: Suhrkamp Verlag, 1995.

; De GIORGI, Raffaele. Teoria della società. Milano: Franco Angeli, 2013 (1992). RAMOS, Graciliano. Vidas secas. São Paulo: Saraiva, 2008.

SANTI, Thais. Belomonte: a anatomia de um etnocídio. El País, 1 dez. 2014. Entrevista concedida a Eliane Brum.

SASSEN, Saskia. Globalization and its discontents. New York: New Press, 1999.

SAVIGNY, Friedrich C. Juristische methodenlehre. Stuttgart: Koehler, 1951.

. System des heutigen römischen Rechts. Aalen: Scientia Verlag, 1973. v. 1.

SOMMER, Manfred. Die Selbsterhaltung der Vernunft. Stuttgart-Bad Cannstatt: Fromman-Holzboog, 1990.

STANDING, Guy. The Precariat: the new dangerous class. London: Bloomsbury Academic, 2011.

THOMPSON, Edward P. Customs in common. New York: New Press, 1991.

WELZEL, Hans. Naturrecht und materiale Gerechtigkeit. Göttingen: Vandenhoeck \& Ruprecht, 1990.

1 GRIMM, Dieter. Die Zukunft der Verfassung. Frankfurt: Suhrkamp Verlag, 1991.; e, em particular nas relações aos temas dos quais nos ocuparemos nos próximos parágrafos. Id., Die Zukunft der Verfassung II: Auswirkungen von Europäisierung und Globalisierung. Frankfurt: Suhrkamp Verlag, 2012. Cf. anche FERRAJOLI, Luigi. Diritti fondamentali: un dibattito teorico. Roma-Bari: Laterza, 2001. p. 3-40; p. 121-175; p. 277-370.

2 Sobre essa questão, cf. DE GIORGI, Raffaele. El futuro de la Justiciabilidad de los derechos humanos. In: ARGUMENTACIÓN JURISPRUDENCIAL - MEMORIA DEL CONGRESO INTERNACIONAL DE ARGUMENTACIÓN JURÍDICA: JUSTICIABILIDAD DE LOS DERECHOS, 4., 2014, México. Anais... México: Suprema Corte de Justicia de la Nación, 2014. p. 407-429.

3 LUHMANN, Niklas. Das Recht der Gesellschaft. Frankfurt: Suhrkamp Verlag, 1995. p. 574 e ss.

4 STANDING, Guy. The Precariat: the new dangerous class. London: Bloomsbury Academic, 2011.

5 LUHMANN, Niklas. Grundrechte als Institution. Berlin: Dunker \& Humblot, 1965.

6 Cf. LUHMANN, Niklas. Das Recht der Gesellschaft, op. cit., p. 233 e ss.; 484, s.

7 WELZEL, Hans. Naturrecht und materiale Gerechtigkeit. Göttingen: Vandenhoeck \& Ruprecht, 1990.

8 KANT, Immanuel. Die Methaphysik der Sitten. Frankfurt: Suhrkamp Verlag, 1982. v. 8. p. 345. Die Qualität des Menschen, sein eigener Herr (sui iuris) zu sein.

9 KELSEN, Hans. Reine Rechtslehre: einleitung in die rechtswissenschaftliche Problematik. Leipzig: Franz Deuticke Verlag, 1934.

10 KANT, op. cit., p. 329: Tat heißt eine Handlung, sofern sie unter Gesetzen der Verbindlichkeit steht, folglich auch, 
sofern das Subjekt in derselben nach der Freiheit seiner Willkür betrachtet wird. Der Handelnde wird durch einen solchen Akt als Urheber der Wirkung betrachtet, und diese, zusamt der Handlung selbst, können ihm zugerechnet werden.

11 Idem, l.c., : Person ist dasjenige Subjekt, dessen Handlungen einer Zurechnung fähig sind. Cf. DE GIORGI, Raffaele. Azione e imputazione: semantica e critica di un principio nel diritto penale. Lecce: Milella, 1984..

12 SOMMER, Manfred. Die Selbsterhaltung der Vernunft. Stuttgart-Bad Cannstatt: Fromman-Holzboog, 1990; Kant diz com extrema clareza: Grundsatz der Vernunft: ihre Selbsterhaltung, Refl. 1509 (AA XV, 823).

13 LUHMANN, Niklas; DE GIORGI, Raffaele. Teoria della Società. Milano: Franco Angeli, 2013 (1992).

14 LUHMANN, Niklas. Grundrechte als Institution. Berlin: Dunker \& Humblot, 1965. p. 53-83.

15 DE GIORGI, Raffaele. Modelos jurídicos de la igualdad y de la equidad. In: mentales en la sociedad moderna. México: Editorial Fontamara, 2015. p. 35-53.

16 LUHMANN, Niklas; DE GIORGI, Raffaele. Teoria della società. Milano: Franco Angeli, 2013 (1992). cit., cap. 3: Evoluzione. p. 169-246.

17 FOUCAULT, Michel. Surveiller et punir: naissance de la prison. Paris: Gallimard, 1993.

18 THOMPSON, Edward P. Customs in common. New York: New Press, 1991. cf. GÖTZ, Norbert. Moral economy: its conceptual history and analitical prospects. Journal of Global Ethics, United States, v. 11, p. 147-162, 2015.

19 SANTI, Thais. Belomonte: a anatomia de um etnocídio. El País, 1 dez. 2014. Entrevista concedida a Eliane Brum.

20 SANTI, Thais. Belomonte: a anatomia de um etnocídio. El País, 1 dez. 2014. Entrevista concedida a Eliane Brum. A Procuradora da República Thais Santi conta como a terceira maior hidrelétrica do mundo vai se tornando fato consumado numa operação de suspensão da ordem jurídica, misturando o público e o privado e causando uma catástrofe indígena e ambiental de proporções amazônicas, El País, 1dez. 2014.

21 SASSEN, Saskia. Globalization and its discontents. New York: New Press, 1999.

22 KAFKA, Franz. Vor dem Gesetz (1915). In:____. Der Proceß. Frankfurt: Insel Verlag, 1990. v. 3. p. 226 e ss.

23 ALEXY, Robert. Obra de referência: Theorie der grundrechte. Frankfurt: Suhrkamp Verlag, 1987; Id. Theorie der juristischen argumentation: die Theorie des rationalen Diskurses als Theorie der juristischen Begründung. Frankfurt: Suhrkamp Verlag, 1983.24 v. SAVIGNY, Friedrich C. Juristische Methodenlehre. Stuttgart: Koehler: 1951. p. 37. (ed. Wesenberg, Segundo a elaboração de J. Grimm) e System des heutigen römischen Rechts. Aalen: Scientia Verlag, 1973. v. 1. p. 36. Cf. DE GIORGI, Raffaele, Ciência do direito e legitimação: crítica da epistemologia jurídica alemã de Kelsen a Luhmann. Curitiba: Juruá, 2017.p. 37 e ss.

25 Cf. LUHMANN, Niklas; De GIORGI, Raffaele. Teoria della società. Milano: Franco Angeli, 2013 (1992). cap. 5.

26 RAMOS, Graciliano. Vidas Secas. São Paulo: Saraiva, 2008. 


\title{
TOWARDS AN ECOLOGY OF HUMAN RIGHTS
}

\begin{abstract}
This article brings forward a discussion on Human Rights and how they are characterized by great expectations that match systematic disillusions. As such, the article presents a realist reflection on the invention of the individual as a unique subject, rational and free, while allowing for the comprehension of the semantic structure that made it possible for Human Rights to thrive in modern society, their function and special contribution to the evolution of society. The article also intends to reflect upon the specific character of the function of Human Rights, on the paradox of its semantics, on its contribution to the production of singularities and the excess of such production. Thus, the article proposes to set the scene for a possible ecology of Human Rights.
\end{abstract}

Keywords: Human Rights. Modern Society. Invention of the Subject. Singularity. Ecology.

Submetido: 20 jun. 2017

Artigo convidado 